\title{
Determination of the optimal number of runs of dehairing in fibers of patagonian cashmere goats
}

\begin{abstract}
The AM2 dehairing technology reduces the objectionable fibers content of shorn fleeces. Nonetheless, it also reduces fiber length and the final yield is affected by the successive runs through the dehairing machine, though it allows specifying the number of passes required for each lot. The aim of this work is to establish the number of passes that the machine should make until optimal performance is reached from an objectionable fibers content, fiber length, fiber diameter and yields to dehairing perspective. Work was carried out on fiber sheared from Argentine north Patagonian goats. From each run, samples were extracted for processing at the laboratory, and measurements comprised: yield to dehairing (\%Y), objectionable fiber content (w/w) (FOC), average fiber length (FL) and average fiber diameter (FD).I t was concluded that the lowest $\% \mathrm{Y}$ was obtained in run 10 , the minimum FOC in run 6, the lowest FL in run $7(2.6 \mathrm{~cm})$ and the lowest FD in run 5 (18.1microns). It is concluded that, if 4 runs are assumed to be optimal to obtain less than $1 \%$ of objectionable fibers, a $\%$ Y: $35-37 \%$, FOC: $0.2 \%$, FL: $3.5 \mathrm{~cm}$ and FD: $18.3 \mu \mathrm{m}$ would be obtained.
\end{abstract}

Volume 4 Issue 3 - 2018

\author{
Frank EN,,${ }^{1,2}$ Hick MVH, ${ }^{1,2}$ Castillo MF,' \\ Seghetti Frondizi DG ${ }^{3}$ \\ ISUPPRAD Program, IRNASUS-CONICET-UCC, Argentina \\ ${ }^{2} U \mathrm{CHA}-$ National University of La Rioja,Argentina \\ ${ }^{3}$ Private Textile Company,Argentina
}

Correspondence: Eduardo Frank, Designation Professor, PhD, Catholic University of Cordoba, UNLAR, Armada Argentina 3555. Córdoba, Argentina, Tel 54935 I 4938030,

Email frank.agro@ucc.edu.ar

Received: April 21, 2018 | Published: May 25, 2018

Keywords: cashmere, dehairing, optimization, Patagonian

Abbreviations: FOC, objectionable fiber content; FL, fiber length; FD, fiber diameter; CFP, coarse fibres percentage

\section{Introduction}

The dehairing process is the process in which the cashmere fibers are separated from the coarse fibers and impurities. Since the mechanization of the process, cashmere dehairing and processing have been kept secretive and very little information has been published about them.

The information secrecy between processors and machine manufacturers kept both sides apart and affected the development of the cashmere dehairing process. The cashmere processing companies, which invented and developed dehairing machines did not have information about machine engineering while textile machinery manufacturers who have tried building dehairing machines lacked the insight from cashmere fiber processing. ${ }^{1}$

The main actions taking place during dehairing are the opening of the scoured fleece into individual fibers by separating the coarse guard hairs from the fine ones and transferring the partially dehaired fibres from one dehairing point to another one. This implies a certain number of passes or runs at the different dehairing points.

In order to consider a dehairing process as an effective one, the three main actions should be as effective as possible.

A study investigating the effects of the attributes of raw cashmere over the dehairing efficiency and dehaired length cashmere fibre, show that raw cashmere attributes associated with a more efficient processing are the following: white color; longer raw cashmere; greater fiber curvature; less vegetable matter; average fiber length and absence of visible felt-like aspect. ${ }^{2}$ The percentage of coarse hair in the end product of dehairing process decline with an increasing number of dehairing points, but this has an adverse effect on machine productivity and fiber length average. ${ }^{3}$ This is even more difficult, considering that in the case of Argentina, the raw material to be dehaired comes from a sheared fleece, that is, not combed on the goat. ${ }^{4}$

In the process of mechanical dehairing of Kazakhstan goat down, the average length of true coarse fibers decreased with each pass and the overall decline was $10.5 \mathrm{~mm}$ or $25.5 \%$, from the sixth to the eighth-from 36.6 to $32.4 \mathrm{~mm}$ and thus the short lower level was reached. During processing the average fibers fineness decreased 1.19 micrometers or $7.28 \%$. Thinning of down fibers on the first three passes was $0.80 \mathrm{~mm}$ or $4.8 \%$, and for the last three passes, from the fifth to the eighth, it decreased again by $0.40 \mathrm{~mm}$ or $2.4 \%$. Down fineness reduction is considered as a consequence of a decrease in the specific content of long fiber fraction, which is an intermediate fiber type with higher fineness than down fibres. ${ }^{5}$

The development, on the other hand, of the AM2 dehairing technology has allowed establishing Patagonian cashmere production as a new livestock industry. This process is complex and requires a high degree of precision in its execution so that its operations will become profitable.

Basically it reduces the objectionable fiber content from shorn fleeces, but also reduces the length of the fiber and the final yield is affected by the successive runs through the machine. The subsequent passes reduce the length of the resulting fiber, the yields in the dehairing down and increase the cost of processing concomitantly. ${ }^{6}$

The technology allows individual control of each run quality and therefore enables a sound decision about the number of passes required for each lot. The aim of this work was to establish by means of a group of trials with AM2 dehairing technology, the number of passes made by the machine until reaching a minimum and also the number of passes optimal from the point of view of objectionable fiber content, fiber length, fiber diameter and the yields of dehairing. 


\section{Material and methods}

Three different batches of sheared fiber from north Patagonia goats were processed; they were dehaired until the process seemed unchangeable by macroscopically visual assessment (number of passes: 12). Each lot was classified according to the length ratio of the coarse fiber to the length of the fine fiber and according to the crimp frequency, fulfilling the requirement to be graded as commercial cashmere and there were only slightly different in down yield for potential dehairing. In each pass (run) product and by-product was weighed to the nearest $\mathrm{mg}$, measured to the nearest $\mathrm{mm}$, and in turn samples were extracted for diameter in laboratory processing (micro projector).

The variables measured were: yield to dehairing ( $\mathrm{Y}, \%)$, fiber objectionable content (w/w) (FOC, \%), average fiber length (FL, mm) and average fiber diameter $(\mathrm{FD}, \mu \mathrm{m})$.

The variables obtained were fitted with a polynomial regression model on the number of runs as:

$$
\hat{y}=\hat{\beta}_{0}+\hat{\beta}_{1}+\hat{\beta}_{2} x
$$

Where,

$\hat{y}$ Response variable for $\% \mathrm{Y}, \mathrm{FOC}, \mathrm{FL}$ or $\mathrm{FD}$

$\hat{\beta}_{1}$ First order term of $\mathrm{N}^{\circ}$ runs

$\hat{\beta}_{2}$ Second order term of $\mathrm{N}^{\circ}$ runs

$x \mathrm{~N}^{\circ}$ of dehairing runs

And the first derivative of the function was calculated as:

$$
\begin{gathered}
\frac{d \hat{y}}{d x}=\frac{\lim }{\Delta x \rightarrow 0}\left(\hat{\beta}_{1}+2 \hat{\beta}_{2} x+\hat{\beta}_{2} \Delta x\right)=\hat{\beta} .+2 \hat{\beta} . x \\
\text { if } \hat{\beta}_{1}+2 \hat{\beta}_{2} x=0 \\
\text { then }: x=\frac{\hat{\beta}}{2 \hat{\beta}_{2}}
\end{gathered}
$$

The value of the variable $(x)$ for the run that gets the minimum value was estimated, and with the same function, the value of variable from an expected optimal value was also calculated.?

\section{Results and discussion}

By the three trials a minimum of dehairing yield at around step 10 was obtained. If the 4 th pass is considered to be the optimum one,$^{8}$ a yield between $35-37 \%$ is obtained.

The lowest yield is obtained around run number 10 . This pass number is given by considering the first derivative of the tendency curve function (Eq. 1) as null. The solution of this equation is 10.4 to-10.6runs.

The repeatability of the three tests with respect to yield appears consistent (Table 1) and equations showing a similar degree of fitting (R2: 0.93-0.95). A similar dehairing yield of 32.5 (sd: 13.9) \% was obtained in a recent population work with fibre from the same origin (Figure 1). ${ }^{4}$

The lowest FL is obtained on the run $7(2.6 \mathrm{~cm})$, but in the run 4 the average length is still $3.5 \mathrm{~cm}$, close to the industrial optimum which is $3.8 \mathrm{~cm}$. With Iranian shearing cashmere a mean fibre length has decreased from $59.8 \mathrm{~mm}$ (at raw state) to $46.1 \mathrm{~mm}$. Passing the same material through the second dehairing unit the fibre breakage was larger.

Table I Regression equations, maximum and minimum derivate value of three dehairing trials for dehairing yield

\begin{tabular}{lllll}
\hline Trials & $\begin{array}{l}\text { Prediction } \\
\text { equations }\end{array}$ & $\begin{array}{l}\text { Min. } \\
\text { dehairing } \\
\text { point }\end{array}$ & $\begin{array}{l}\text { Min. } \\
\text { yield } \\
\text { point }\end{array}$ & $\begin{array}{l}\text { Yield 4 } \\
\text { runs }\end{array}$ \\
\hline & $\begin{array}{l}\mathrm{y}=0.78 \mathrm{x}^{2}-16.54 \mathrm{x} \\
+104.29\end{array}$ & $10.6 \mathrm{runs}$ & $17 \%$ & $35 \%$ \\
$\mathrm{~T} 1$ & $\mathrm{R}^{2}=0.95$ & & \\
& $\mathrm{y}=0.73 \mathrm{x}^{2}-15.6 \mathrm{x}$ & & & \\
$\mathrm{T} 2$ & +101.73 & $10.6 \mathrm{runs}$ & $19 \%$ & $36 \%$ \\
& $\mathrm{R}^{2}=0.93$ & & & \\
& $\mathrm{y}=0.80 \mathrm{x}^{2}-16.55 \mathrm{x}$ & & & \\
$\mathrm{T} 33$ & +103.16 & $10.4 \mathrm{runs}$ & $17 \%$ & $37 \%$ \\
& $\mathrm{R}^{2}=0.93$ & & & \\
\hline
\end{tabular}

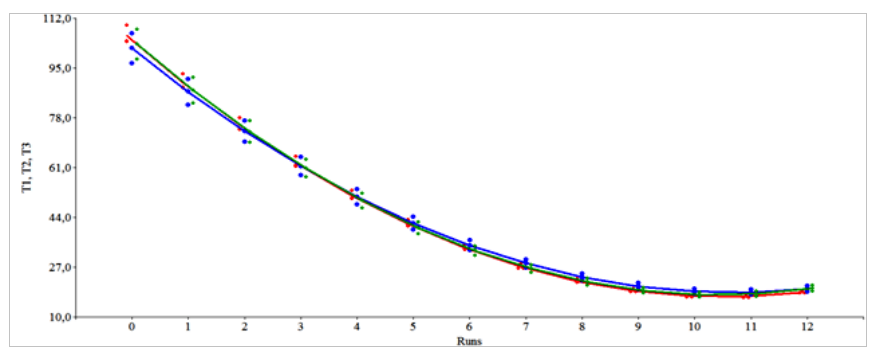

Figure I Length reduction by dehairing runs in the three dehairing trials.

This amount will reach $31.3 \%$ which is $11.8 \%$ more than the first dehairing pass and mean fibre length decreases to $41 \mathrm{~mm}$ which is $7.1 \mathrm{~mm}$ shorter than the first pass.

Therefore, the author assumed that by increasing the number of dehairing passes the fibre breakage increased and decreased the fibre mean length, ${ }^{9}$ similar to the predicted results obtained under simulation (Table 2). ${ }^{3}$

A reduction of the fiber length of $24.5 \%$ was obtained in cashmere dehairing from Kazakhstan, in Run $8 .^{5}$

The minimum coarse fibres (CFP) is obtained on the run 6 and it means a negative value (less than zero), which reduces the accuracy of the calculated derivative (Figure 2).

While working with Iranian fibre, and starting from a content of $34.9 \%$ this is reduced dramatically to $0.7 \%$ in the first pass, decreasing in the second to $0.3 \%{ }^{9}$ In Kazakhstan cashmere, through 8 runs a reduction of $17 \%$ was achieved, but it was hair combed on the animal. ${ }^{5}$ Meanwhile, the smaller diameter fiber (FD) emerges in run 5 (18.1microns).

Only a 9.4\% reduction in FD is obtained by dehairing in the second run in Iranian cashmere. ${ }^{9}$

If it is assumed that, according to reference and own observations, four runs are optimal for obtaining fewer than $1 \%$ of objectionable fibers, by that number of passes a yield $(\mathrm{Y})$ between $35-37 \%$, is 
obtained, a percentage of coarse fibers (CFP) of $0.2 \%$, a fiber length (FL) of $3.5 \mathrm{~cm}$ and a fiber diameter (FD) of 18.3 microns (Figure 3 ).

The difference in work efficiency in the technology used (AM2), may be due to a marked improvement over traditional methods of dehairing, including laboratory methods.

Table 2 Reduction of coarse fibre percentage (CFP), fibre length (FL) and fibre diameter (FD) by successive dehairing passes. Regression, minimum, maximum an optimal level

\begin{tabular}{lllll}
\hline $\begin{array}{l}\text { Fibre } \\
\text { variables }\end{array}$ & $\begin{array}{l}\text { Prediction } \\
\text { equations }\end{array}$ & $\begin{array}{l}\text { Min. } \\
\text { dehairing } \\
\text { point }\end{array}$ & $\begin{array}{l}\text { Min. } \\
\text { variable } \\
\text { point }\end{array}$ & $\begin{array}{l}\text { Num. } \\
\text { runs } \\
\text { (optimal } \\
\text { level) }\end{array}$ \\
\hline CFP & $\begin{array}{l}\mathrm{y}=1.10 \mathrm{x}^{2}- \\
13.46 \mathrm{x}+36.44\end{array}$ & 6.2 runs & $4.70 \%$ & $4(0.2 \%)$ \\
& $\mathrm{R}^{2}=0.61$ & & & \\
$\mathrm{FL}$ & $\mathrm{y}=0.10 \mathrm{x}^{2}-$ & $6.6 \mathrm{runs}$ & $2.6 \mathrm{~cm}$ & $4(3.5 \mathrm{~cm})$ \\
& $1.37 \mathrm{x}+7.1$ & & & \\
& $\mathrm{R}^{2}=0.93$ & & & 4 \\
FD & $\mathrm{y}=0.14 \mathrm{x}^{2}-$ & $5.3 \mathrm{runs}$ & $18.1 \mu \mathrm{m}$ & $(18.3 \mu \mathrm{m})$ \\
& $1.501 \mathrm{x}+22.06$ & & & \\
& $\mathrm{R}^{2}=0.81$ & & &
\end{tabular}

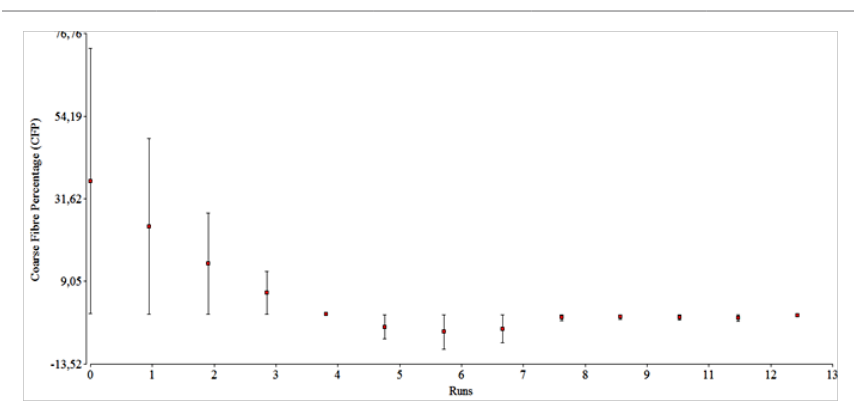

Figure 2 Reduction of CFP in relation to successive passes on the AM2 dehairing machine.

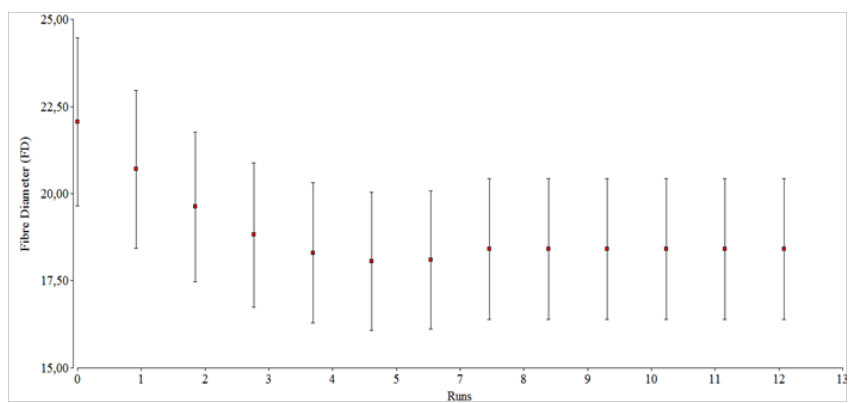

Figure 3 Reduction of fibre diameter through successive dehairing passages on the AM2 dehairing machine.

\section{Conclusion}

It is concluded that the optimum number of runs in AM2 dehairing technology for cashmere shearing from Patagonian goats should not exceeded an amount of about 4 runs. With this number of passes appropriate quality cashmere for international requirements is obtained in the AM2 dehairing machine. All three trials also showed high repeatability of the process and the degree of adjustment related to coarse fiber disappearance, yield, length shortening and diameter reduction is good enough to predict the number of runs required by the textile industry for certain requirements

\section{Acknowledgements}

To the Federal System of Science and Technology (PFIP) that through the province of Neuquen provided the facilities to implement the project: 'Producción Sustentable de Fibras Especiales en Ecosistemas Semiáridos del Norte Neuquino'.

\section{Conflict of interest}

The author declares not to have any conflict of interest in relation to this article with any person or any institution of our country Argentina.

\section{References}

1. Singh A. A study on dehairing of Australian cashmere fibres. Victoria: Deakin University; 2003. 232 p.

2. McGregor BA, Butler KL. The effects of cashmere attributes on the efficiency of dehairing and dehaired cashmere length. Textile Res $J$. 2008;78(6):486-96.

3. Algaa S, Magel M. Investigation and optimization of the mechanical dehairing of unsorted fibres of cashmere goat, camel and yak. Melliand Textilberichte. 1992;73(11):860-65.

4. Frank EN, Hick MVH, Russano D, et al. Sources of variation in fibre production and quality traits source of variation in down-bearing Patagonian goats and implications for developing a cashmere industry. Small Rum Res. 2017;150:60-9.

5. Imasheva A, Otinshiev M, Alikhanov D, et al. Development of technology and means of cashmere down processing. Bulg J Agric Sci. 2014;20:98087.

6. Frank EN, Hick MVH, Prieto A, et al. Effects of the unmasked on the quality of fiber obtained from South American camelids and Patagonian Creole goats. Argentine Magazine Animal Production. 2009;29(Supl 1):134-35.

7. Stewart J. Calculus: Early Transcedentals. Boston: Cegance Learnes; 2012.

8. Msahli S, Harizi T, Sakli F, et al. Effect of the dehairing dromedary hair process on yield, fibre diameter, fibre length and fibre tenacity. Textile Research Institute. 2008;99(5):393-98.

9. Talebpour F. Effect of dehairing process on Iranian cashmere fibre properties. International J Sheep \& Wool Science. 2005;53(1):57-69. 